\title{
Cross Boundary Phenomenon Analysis: Printmaking Artists' Creation of Oil Paintings
}

\author{
Liang Shang ${ }^{1}$, Xiaofeng Liü, * \\ ${ }^{1}$ The Affiliated Middle School of China Central Academy of Fine Arts, Beijing, China \\ ${ }^{2}$ School of Publishing, Printing and Art Design, University of Shanghai for Science and Technology, \\ Shanghai, China \\ ${ }^{*}$ Corresponding author
}

Keywords: Print; Cross Boundary; Oil Painting.

\begin{abstract}
Since 1980s, teachers in printmaking departments of fine arts academies have cultivated a large number of printmaking artists with broad vision. The training on printmaking helps these artists to build up creativity and courage to integrate various resources. Some of them do not stay in the field of printmaking; they try to cross the boundary, and take up other forms of artistic creation. Through presenting examples and relatively analyses, the author tries to explore the relationships between the phenomena and present situations of their specialized training and cross boundary artistic creation.
\end{abstract}

\section{Introduction}

Since 1980 s, teachers in printmaking departments of fine arts academies have cultivated a large number of printmaking artists with broad vision. The training on printmaking helps these artists to build up creativity and courage to integrate various resources. Some of them do not stay in the field of printmaking; they try to cross the boundary, and take up other forms of artistic creation.

For example, a number of artists graduated from Printmaking Department of China Central Academy of Fine Arts, like Bing Xu, Meng-bo Feng, Hao Hong, Fei Teng, Chuan Wang and Lu Yao, are playing active roles in the art field. Their artistic practices have expanded the influence of printmaking artists in modern times. Artists graduated earlier tend to create oil paintings; these painters include Li-jun Fang, Wei Liu, Xin-ping Su, Ping Tan, Wen-zhou Chen, Hua-xiang Wang, Jun Guang, Zhao-yang Yin, Jian-fei Kang, Ling Wen, Si Peng and the art group named "They". Techniques and ideas of printmaking endow these artists with distinctive artistic features, and help them to play more important roles in artistic creation.

\section{One.}

With the development of mass media, image has developed beyond people's expectation since 1960s in Western countries. Contemporary art has been far away from classical art forms, while reproduction techniques make large quantity of recreational reproductions. Reproduction becomes the symbol of modernity, while art works with uniqueness are a kind of "out-of-date". But uniqueness remains one of the most important judgment standards on value of art works. Walter Benjamin believed that the "aura" of a piece of art work came from its uniqueness and irreproducible feature, and claimed that mechanical reproduction withered this "aura". The reproduction of the public images is opposite to art markets, but some artists combine modern concept with the "uniqueness" of oil paintings, and achieve great success. Sometimes, images in their works do not have special meaning, but these simple and flat images are in line with the feature of reproduction in advertising age, and are easy to be spread and memorized. In addition, another character of print, planar expression, can be applied to oil painting. Combined with the creation of skillful artists, these works inspire viewers who get tired of traditional modeling and dense colors in oil paintings created by professional oil painters. Oil paintings drawn by printmaking artists become the focus of contemporary art.[1] 
When creation prints, students in printmaking department need to realize conversion of two levels: one is the conversion from visual to visual, the other is the conversion from visual to thinking. In the teaching process, teachers emphasize the "series" of works. A series of pictures should consist of 8 to 10 paintings. In the long-term creation, artists are able to get their own symbols. Holding this creation concept, printmaking artists are able to create new expression methods when they draw oil paintings.

Compared with regular painting, prints are created indirectly. Print artists need to emphasize each step in production process. But Ping Tan often exchanges the features of prints and regular painting, and make prints as direct as portrait painting. Some of his prints are completed after one stroke; when printing, he tries to avoid inevitability, and gives full play to accidental elements. This creation concept comes from portrait painting, and is used in printmaking. At the same time, Tan applied the overprint method in printmaking to portrait painting. Li-jun Fang, who was good at black and white woodcut prints in school years, introduced the expression language of sketches into oil painting. He ignores the change of colors, and focuses on the proper expression of concepts. The famous image "bare head ruffian" was created under his unique painting method "oil painting sketch". Hua-xiang Wang's paintings are as bold as woodcut. Large color lumps and beautiful background colors show his color matching skills which is trained in silk screen printmaking.

Printmaking artists' attempt on oil painting creation brings new power to oil painting field, and enriches the concepts of oil painting creation. Xian-ting Li once recalled a story told by Li-jun Fang many years ago. When he painted the first series of big head pictures, Yu Xiao, who had graduated from Mural Painting Department and had drawn oil paintings for many years, said, "I don't think your paintings belong to oil painting." Fang replied that, "it doesn't matter". Xin-ping Su once studied painting techniques, but then he found that he was trapped by these traditional rules. So he completely abandoned the study of skills, and began to draw pictures according to his own will. Now he does not rely on photos, or use the concept of image appropriation in pop art. Images created by him are more closely related to humans' living experience and survival situation. Wen-zhou Chen calls himself as "artist on the cliff". He draws the element of time in his works, usually dawn or dusk in the suburb of cities. Chen once said, what he really cared was his own feeling, rather than the standards of oil painting creation. The artists group "They" does not obey to traditional norms, either. They tried to find the "accidental feeling" through strokes, but then they found it deviated from their creation motivation. So afterwards, group members regard "eliminate languages" as their creation concept.

It can be seen from above introduction, though these printmaking artists use oil painting materials to create oil paintings, they do not follow the development path of classical painting, or the mainstream of Chinese oil painting. They like using these materials to express their thoughts and feelings, and different artist has different artistic ideas and language features. Getting rid of traditional rules and restrictions, these artists provide themselves with innovation space.

\section{Two.}

When talking about their creation of oil paintings, all these artists who studied printmaking in art academies mention that, oil paintings are easy to be created. Prints creation, however, requires high technical requirements, complex production process and strict operation procedures. The creation of some kinds of prints needs huge number of tools and materials. Artists' pay and reward are not proportional, especially in their early stage of artistic creation, when survival is an important creative motivation. In addition, as a kind of painting art with profound traditions, great artists and famous works, oil paintings are known throughout the world. Meanwhile, the unique media of oil painting raise works' prices in the art market, which opens the door of artistic creation for young artists.

In addition, mimeograph prints, woodblock prints and almost all other forms of prints cannot be created without machines. These machines are expensive. Students in college are access to these materials and machines, but after graduation, the majority of them are faced with relatively difficult creation environment, and do not have conditions to create prints. The lack of public print workshops and related promotional agencies also affect the survival of printmaking artists. At present, people who are able insist on creating prints are basically teachers of printmaking departments, or engage in second career to support themselves. Creating prints cannot sustain their living. 
Woodcut prints are simple and easy to be replicated. Thus, in the revolutionary period, they became the most effective and direct artistic way to publicize, and was promoted in factories and rural areas. Oil paintings and traditional Chinese paintings, however, have high degree of technology difficulties, and cannot be accepted by ordinary people easily. In this way, prints become a primary-level artistic form with low technical and cultural levels. As time goes on, people gradually form a bias against print, and believe that oil paintings and Chinese paintings are refined and elegant art, while printmaking is popular art. During Cultural Revolution, prints became the three main forms of art with revolutionary model opera and New Year paintings, which strengthened the bias.

In modern western society with industrial civilization, a large number of middle class viewers appreciate prints with industrial civilization features. In Europe and Japan, prints are the best selling works of art; most galleries sell prints to meet the requirements of private consumption. However, Chinese people have their own collection preferences and habits, and in paper art field, they tend to buy Chinese paintings. At the same time, the number of the middle class viewers who have received art education is not large. People do not understand prints, so there is no corresponding print market in China. In addition, the mature public art education environment has not formed. In art textbooks or art history books for popularization, oil paintings are more common. People are familiar with oil painting masterpieces like Monalisa, Liberty Leading the People, and Founding Ceremony, but they know very little about prints.

Print collectors in China are mainly printmaking enthusiasts, not artistic collectors. That is to say, there are no so-called investors in print collection field. Thus, the prices of print works cannot be lifted. At present, only a small number of galleries in China are selling prints. Without the operation of gallery agents, printmaking artists cannot publicize themselves. Though a small number of people can get economic benefits in printmaking, the overall situation of domestic print market is very difficult. Most of art galleries only display large number of oil paintings and Chinese paintings; print exhibitions held by art institutions and galleries are difficult to find. So now in China, there are no good displaying platforms for printmaking artists.[3]

\section{Three.}

The newly-developing woodcut marks the beginning of realism in modern art of China. It displays intellectuals' social conscience and cultural consciousness, which are superior to kills and forms, and form the soul of prints. Bing Xu once commented, "art in liberated areas comes from social practice, rather than technical improvement. It bears no relationship with political pragmatism, and it overcomes the shortcomings of art. It is not conservative, or xenocentric. It is a brand-new kind of art, which represents the most advanced thought of arts at that time."

Bing Xu, Understanding Gu Yuan, J. Artist Newsletter. 1 (1997)

It is very important for an artist to have "intellectual's conscience about the living conditions of human being". Then, do contemporary printmaking artists still have this kind of pioneering spirit? During revolutionary period, Yan-an prints had clear critical direction. Due to the different environment and ideology of times, contemporary printmaking artists now express their own existence and life experience. Their experience does not directly link to the fate of our country or the overall interests of the society. However, it is still necessary for contemporary painters to care the society and ask questions.[3]

The reproduction of prints also has dissemination significance of cultural enlightenment. In China, except woodcut, all kinds of prints came from west. Innovation cannot be achieved without learning and inheriting. As a big manufacturing country, China is lack of innovation. It is the microcosm of current society, and the common problem of prints and other forms of art. Innovation should be taken place in concept level and technique level at the same time. For instance, though Andy Warhol made breakthrough in concept by his screen prints, corresponding technique and language are far from his artistic declaration. These are spaces to be explored by today's artists.

However, after passing the entrance exam of fine arts academy and receiving art education in college for four years, less than a quarter of graduates choose to continue their careers in artistic creation. The majority of art-major graduates choose other development directions. For nearly two 
decades, printmaking department graduates are trying to "cross the boundary". They do not only active in contemporary art field, but also take leading positions in art education. Printmaking artists have various abilities, and have made remarkable achievements. But we cannot ignore the problem of talent loss.

So, should art workers maintain love and loyalty to their profession? When seeking new kinds of artistic expression, print artists stop exploring printmaking language, is it a pity? It is similar to the problem of department division in fine arts academies. In university, students spend almost ninety percent of their time in a specialized technique, and do not have enough time and opportunity to learn and study other majors. Their comprehensive abilities develop in an unbalanced way, and they are curious about other professions. At the same time, now people do not address artists by their creation methods, titles like oil painters, Chinese painters and printmaking artists are less heard. In well-known international art institutions, these disciplines are collectively referred as Fine Art, and there are various technical studios under it.

To sum up, this paper discusses the phenomenon of "cross boundary" which exists in a specific period of time and region. But it is undeniable that every artist will gradually focus on a particular field and carry on in-depth exploration. This field will become the label of the artist. However, when creating artistic works, artists should not trap themselves in limited materials and traditional concepts. They need to give full play to their own advantages, and combine formal language with concept in a most effective way. Thus, they can provide ultimately enlightenment for nowadays and future human society.

\section{References}

[1] Y. Yi, Crisis of originality: reflection on the creation of oil paintings in the past three decades, J. Literature and Art Studies. 01(2009) 102-110.

[2] F.G. Qi, Context conversion of Chinese prints in twentieth century, J. Literature and Art Studies. 06 (1997) 116-131.

[3] A.M. Zhou, What are prints? What can prints do? ---- "Context and Transformation of Contemporary Print: Chinese Printmaking Forum" Overview, J. Art. 09 (2011) 94-98. 